JRRD

\title{
Physical activity barriers and enablers in older Veterans with lower-limb amputation
}

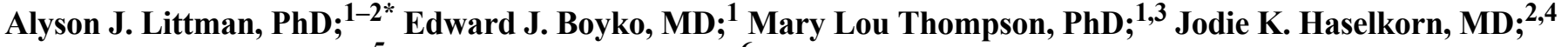
Bruce J. Sangeorzan, MD; ${ }^{5}$ David E. Arterburn, MD $^{6}$

${ }^{1}$ Seattle Epidemiologic Research and Information Center, Department of Veterans Affairs (VA) Puget Sound Health Care System, Seattle, WA; Departments of ${ }^{2}$ Epidemiology and ${ }^{3}$ Biostatistics, University of Washington, Seattle, WA; ${ }^{4}$ Multiple Sclerosis Center of Excellence West, VA Puget Sound Health Care System, Seattle, WA; and Department of Rehabilitation, University of Washington, Seattle, WA; ${ }^{5}$ Center of Excellence for Limb Loss Prevention and Prosthetic Engineering, VA Puget Sound Health Care System, Seattle, WA; Department of Orthopaedics and Sports Medicine, University of Washington Medical Center, Seattle, WA; and Department of Orthopaedics and Sports Medicine, Harborview Medical Center, Seattle, WA; ${ }^{6}$ Group Health Research Institute, Seattle, WA
\end{abstract}

\begin{abstract}
Little is known about the types of physical activities that older individuals with lower-limb loss perform, correlates of regular physical activity (PA), and barriers and facilitators to PA. We conducted an exploratory study in 158 older Veterans from the Pacific Northwest with a partial foot (35\%), below-knee (39\%), and above-knee (26\%) amputation. Ninety-eight percent of survey respondents were male, on average $65 \mathrm{yr}$ of age and 15 yr postamputation; $36 \%$ of amputations were trauma-related. The most commonly reported physical activities were walking/ wheeling (65\%), muscle strengthening (42\%), exercise prescribed by a physical or occupational therapist (32\%), and gardening (31\%). Forty-three percent were classified as physically active based on weekly moderate- and vigorous-intensity PA. History of vigorous preamputation PA was positively associated with being active, while low wealth and watching $5 \mathrm{~h} / \mathrm{d}$ or more of television/videos were inversely associated. While pain- and resource-related barriers to PA were most frequently reported, only knowledge-related and interest/motivation-related barriers were inversely associated with being active. Family support and financial assistance to join a gym were the most commonly reported factors that would facilitate PA. To increase PA in the older amputee population, interventions should address motivational issues, knowledge gaps, and television watching; reduce financial barriers to exercising; and consider involving family members.
\end{abstract}

Key words: activity scale, amputee intervention, barriers, exercise, facilitators, lower-limb amputation, partial foot amputation, physical activity, trauma-related amputation, Veterans.

\section{INTRODUCTION}

Physical activity (PA) offers numerous physical and mental health benefits and is recommended for individuals of all ages, including those with chronic conditions and functional limitations [1]. Walking is the most commonly performed PA in the general population, particularly in older adults [2]. However, in persons with a lower-limb amputation (LLA), walking requires additional skill, strength, and energy [3-4]. Furthermore, walking and other physical

\footnotetext{
Abbreviations: $\mathrm{AKA}=$ above-knee amputation, $\mathrm{BKA}=$ below-knee amputation, ICD = International Classification of Diseases, LLA $=$ lower-limb amputation, MET $=$ metabolic equivalent task, $\mathrm{PA}=$ physical activity, $\mathrm{PASPD}=$ Physical Activity Scale for Individuals with Physical Disabilities, PFA = partial foot amputation, PROMIS = Patient Reported Outcomes Measurement Information System, RR = relative risk, VA = Department of Veterans Affairs, VHA = Veterans Health Administration, VISN = Veterans Integrated Service Network. *Address all correspondence to Alyson J. Littman, PhD; Seattle Epidemiologic Research and Information Center, VA Affairs Puget Sound Medical Center, 1100 Olive Way, Metropolitan Park West, Suite 1400, Seattle, WA 98101; 206-2774182; fax: 206-764-2563. Email: alvson.littman@va.gov http://dx.doi.org/10.1682/JRRD.2013.06.0152
} 
activities may be more challenging because of chronic illnesses that may have led to the amputation [5-6], arthritis [6], the need for specialized prosthetics/equipment, and increased risk of skin ulceration in the residual limb [7]. A 2010 study demonstrated that, contrary to prior beliefs, energy expenditure of walking in persons with a partial foot amputation (PFA) is similar to the energy expended in persons with more proximal amputations [4], indicating that these individuals may also face important barriers to physical activity that have been inadequately studied. Nevertheless, regular PA in people with LLA is critical to prevent further deterioration in physical and psychological functioning, worsening chronic illness burden, and weight gain [810]. In the United States, approximately 130,000 amputations are performed each year and about 1 in 300 people (over 1 million people) are living with lower-limb loss [1112]. The Veterans Health Administration (VHA), the largest integrated healthcare system in the United States, cares for over 43,000 men and women with major LLA and at least that many with PFAs [13]. Correspondingly, Veterans represent a large proportion of the U.S. population living with this disability. Because of the Department of Veterans Affairs' (VA's) focus on the health and well-being of persons with limb loss through their Amputation System of Care [13], the VA is an ideal setting in which to test and implement interventions to increase PA in this population.

Recent data on PA levels and its correlates, as well as barriers and facilitators to PA in older individuals with LLA, are scarce and comprise seven studies using a relatively broad definition of activity [14-21]. Prior studies demonstrated that moderate-to-vigorous PA levels were low [1], with most activities being sedentary or of a low intensity [16-17]. In one of the studies, the strongest predictor of current PA was being physically active before the amputation [19]; level of amputation and etiology were not associated with current PA [15,19]. Key barriers to PA included pain; insufficient knowledge of recreational activities, techniques, and facilities available to them; accessibility; material resources; self-consciousness, body image concerns, and stigma; safety concerns; disease/poor health; and lack of interest or perceived benefit/need [15,19-20]. None of these prior studies included individuals with PFAs, and most included only prosthetic users. In addition, most of these prior studies focused on broadly defined recreational activities (e.g., shopping and visiting with friends) rather than activity with the primary purpose of improving or maintaining physical fitness, physical performance, or health.
Because of the greater appreciation of the value and benefits of PA in all people, including those with functional limitations [1]; increased visibility of PA for people with disabilities [22]; improvements in prosthetic devices [23-24]; and a growing awareness of the challenges that people with PFAs may face [4], a contemporary assessment of individuals with lower-limb loss in relation to PA behaviors is needed. This study aimed to help fill existing research gaps by describing, in a sample of older Veterans with varying levels and etiologies of LLA, the types of PA most commonly performed; the demographic-, health-, and amputation-related correlates of PA; and factors that prevent or may promote PA. This information is necessary to tailor existing behavior change interventions and help create a road map for future research studies, and in so doing, improve the quality and quantity of life in individuals with LLA.

\section{METHODS}

\section{Study Population}

We identified potential study participants using VA electronic medical records (Veterans Integrated Service Network [VISN] 20 Data Warehouse) based on (1) having a primary care visit in the 18 mo prior to the data pull (to increase the likelihood that the person's address was up to date and that he/she was a current VA patient); (2) being currently alive; and (3) having an LLA for $\geq 6$ mo based on an International Classification of Diseases (ICD)-9 diagnosis code (ICD-9 895-897.7), prosthetic device or repair code (L5000-L5341, L5610-L5999, L7500-7600, L84008410, L8417-8430, L8440-8460, L8470-8480, L8499), or procedure code (84.10-84.17). VISN 20 is one of 21 integrated service networks within the VA and includes 8 medical centers in Washington, Oregon, Alaska, and Idaho and their affiliated community-based outpatient clinics. We randomly selected 400 individuals of the 2,436 identified with the aim of obtaining at least 150 completed questionnaires.

\section{Recruitment}

Recruitment was conducted using methods described by Dillman [25] and others [26-27] to maximize response rates. All study procedures were approved by the VA Puget Sound Institutional Review Board; a waiver of documentation of written informed consent was received. 


\section{Data Collection and Measures}

The 28-page questionnaire included sections on amputation characteristics, physical activities, diet, weight, health and well-being, and demographic characteristics. Participants reported their level of amputation on the left and right sides of their body, cause of their amputation, and the date of their first amputation. We inquired about their age, education, race/ethnicity, marital status, employment status, and wealth. To assess walking ability, respondents reported whether they typically used a wheelchair or scooter to get around their house and whether they used a prosthesis to walk.

PA level prior to amputation was assessed using a single-item modeled on the Godin PA questionnaire [28]. Participants were asked to report how often they "engaged in any regular activity long enough to work up a sweat (heart beats rapidly)" before their amputation. Response options were "often (5-7 times per week)," "sometimes (2-4 times per week)," and "never/rarely (01 times per week)." This single item has been found to be significantly correlated with objective measures of fitness and body fat [28].

Current PA was assessed based on a modification of the Physical Activity Scale for Individuals with Physical Disabilities (PASPD) and the past-week Modifiable Activities Questionnaire [29-31]. Using the PASPD, we obtained information on the frequency and duration of walking/wheeling, exercises prescribed by a physical or occupational therapist (such as stretching or strengthening, using light weights or bands), and strengthening exercises [29]. The original PASPD questionnaire listed four categories of duration ( $<1 \mathrm{~h}, 1$ but less than $2 \mathrm{~h}, 2-4 \mathrm{~h}$, and $>4 \mathrm{~h}$ ). To better distinguish lower levels of activity, we created five categories ( $<10 \mathrm{~min}$ per day, 10-30 min per day, 31-60 min per day, 1-2 h per day, $>2$ h per day). We used the past week version of the Modifiable Activities Questionnaire [30-31] to assess frequency and usual duration of nine recreational activities (bicycling outdoors or on a stationary bike; swimming laps; other exercise in a pool; golf; bowling; yoga, tai chi, or pilates; karate or other martial arts; yard work; gardening). Participants were asked to report their activity in the past $7 \mathrm{~d}$, which is a standard time frame for self-report instruments to reduce overreporting of PA [32]. Because the survey was administered between June and October 2011, activities listed were those typically performed outdoors and in the summer and fall; additional space was provided for participants to include information for up to two activities not specified.
We calculated weekly duration of PA as the product of weekly PA frequency and usual session duration. We did not assess perceived exertion; intensity of activity was determined based on published metabolic equivalent task (MET) codes, where a MET value of 1.0 is equivalent to sitting quietly [33]. For activities (e.g., walking, swimming, biking) with multiple MET values (as determined by intensity or speed) in the compendium, we selected the higher MET value, with the assumption that activities performed by people with LLA likely require greater energy expenditure than activities done at the same speed or intensity in the general population. We classified activities with a MET between 3 and 5.9 as moderate-intensity activities and $\geq 6$ as vigorous-intensity activities [1]. We classified respondents as “active” if they met Centers for Disease Control and Prevention U.S. Guidelines for Physical Activity [1], which we operationalized as $\geq 75$ min per week of vigorous-intensity activities (e.g., bicycling, swimming, or martial arts), $\geq 150$ min per week of moderate-intensity activity (e.g., walking/wheeling, strength training, pool exercise other than swimming, gardening and yard work), or an equivalent combination of the two (where we doubled minutes of vigorous-intensity PA).

Barriers to PA were assessed using a scale developed by Rimmer et al. [34] that was modified to include items relevant to people with LLA through an iterative process of item development by the research team members, revision based on feedback from rehabilitation clinicians specializing in amputation care, and pilot testing of the survey instrument in a sample of seven individuals with LLA. Respondents were asked to report on a scale of 1 to 5 (1 being "not at all a barrier" and 5 being "very much a barrier") the degree to which the issues presented in Table 1 prevented them from performing PA in the past 4 wk. To understand what factors might promote greater PA, we assessed the extent to which various factors presented in Table 2 would help individuals become or stay physically active (would not help, would help a little, or would help a lot). To get a sense of sedentary behaviors during a typical weekday, we asked about usual hours per day spent watching television and videos [35].

We used the Global Health items from the Patient Reported Outcomes Measurement Information System (PROMIS) to assess physical health status, mental health status, and pain. The PROMIS measures provide highly reliable, precise measures of patient-reported health status [36]. The Global Health instrument includes 10 items, all of 
Table 1.

Usual physical activities before amputation, current physical activities, current sedentary behaviors, and barriers to activity in Northwest Veterans with lower-limb loss. Numbers given are percentage of participants.

\begin{tabular}{|c|c|c|c|}
\hline \multirow[b]{2}{*}{ Activity } & \multicolumn{3}{|c|}{ Level of Amputation" } \\
\hline & $\begin{array}{l}\text { Partial Foot } \\
\quad(n=55)\end{array}$ & $\begin{array}{c}\text { Below Knee } \\
(n=62)\end{array}$ & $\begin{array}{c}\text { Above Knee } \\
(n=41)\end{array}$ \\
\hline \multicolumn{4}{|l|}{ Activity Prior to Amputation: Frequency of Vigorous Exercise } \\
\hline Never/rarely & 32.7 & 23.7 & 22.5 \\
\hline Sometimes (2-4 times/week) & 49.1 & 39.0 & 35.0 \\
\hline Often (5-7 times/week) & 18.2 & 37.3 & 42.5 \\
\hline Exercises prescribed by physical or occupational therapist & 27.3 & 27.4 & 43.9 \\
\hline Exercises performed to increase muscle strength and endurance & 38.2 & 37.1 & 56.1 \\
\hline Yard work & 26.4 & 34.4 & 25.6 \\
\hline Gardening & 31.5 & 29.0 & 32.5 \\
\hline Bicycling outdoors or on stationary bicycle & 9.1 & 11.5 & 17.1 \\
\hline Sedentary behaviors: $\geq 5 \mathrm{~h} / \mathrm{d}$ watching television (including videos on VCR/DVD) & 25.5 & 32.3 & 29.3 \\
\hline \multicolumn{4}{|l|}{ Barriers to Activity ${ }^{\ddagger}$} \\
\hline Pain-related & 50.9 & 59.7 & 46.3 \\
\hline Resource-related & 50.9 & 64.5 & 46.3 \\
\hline Knowledge-related & 20.0 & 32.3 & 24.4 \\
\hline Health-related & 27.3 & 33.9 & 29.3 \\
\hline \multicolumn{4}{|l|}{ Motivation/other } \\
\hline Lack of interest in exercising & 17.0 & 31.2 & 24.4 \\
\hline Fatigue or sleepiness & 27.3 & 30.7 & 20.5 \\
\hline Fear of falling & 16.4 & 12.9 & 25.0 \\
\hline
\end{tabular}

Note: Percentages are based on those with nonmissing responses.

* Partial foot includes unilateral toe $(n=33)$, unilateral transmetatarsal $(n=5)$, unilateral Symes $(n=5)$, bilateral toe $(n=9)$, and transmetatarsal plus contralateral partial foot $(n=3)$; 47 (46 below knee +1 knee disarticulation) of persons with below/through knee amputation had no other amputations, 8 had minor amputation on contralateral leg, 7 had bilaterial transtibial amputations. 36 people with transfemoral amputation had no other amputations, 5 had bilateral transfemoral amputations.

${ }^{\dagger}$ Performed at least one time in previous $7 \mathrm{~d}$. Four or fewer individuals reported bowling; yoga, tai chi, or pilates; and karate or other martial arts.

${ }^{\ddagger}$ Numbers represent proportions of those stating that factor was "very much” a barrier, which was equal to 4 or 5 on a scale from 1 ("not at all a barrier”) to 5 . Items included for each group are as follows: pain-related: (1) "Pain caused by my prosthesis not fitting well," (2) "Phantom limb pain," and (3) “Other pain (for example, in my back, knees, or shoulders)"; resource-related: (1) "Cost of an adapted/sports prosthesis or adapted/sports wheelchair," (2) "The proper prosthetic device or wheelchair to do the exercise that I would like to do," (3) "Cost to join a fitness facility or take exercise classes," and (4) "Transportation to get to a place to exercise (for example, a park or gym)"; knowledge-related: (1) "Knowledge about exercises I can do" and (2) "Knowledge about places to work out”; health-related: (1) "An illness or injury" and (2) "Instructions from my doctor to not bear weight”; lack of interest in exercising: single item; fatigue or sleepiness: single item; Fear of falling: single item; and lack time to exercise: single item.

which are scored on a 5-point scale, with the exception of the 11-point pain intensity item ("How would you rate your pain on average" with $0=$ "no pain" and $10=$ "worst imaginable pain"). We calculated scores on the physical (4 items) and mental (4 items) health subscales. Pain was assessed using the item noted. Item scores were recoded such that for all responses, higher scores reflected better functioning. Pain interference was assessed via a 4-item instrument that inquired about how much pain interfered with (1) day-to-day activities, (2) work around the home, (3) ability to participate in social activities, and (4) enjoyment of life using a 5-point scale [37]. Raw scores for the physical health, mental health, and pain interference measures were converted to standardized $t$-scores, which have a mean of 50 and a standard deviation of 10 , based on the conversion tables provided by the developers [37-38]. 
Table 2.

Overall proportion of participants reporting that factors would help them become or stay active.

\begin{tabular}{lc}
\hline \multicolumn{1}{c}{ Facilitator } & Percent \\
\hline Free or no cost membership to gym & 43.0 \\
Support from spouse or family member & 35.7 \\
Home exercise equipment & 27.6 \\
Specialized equipment to do exercise I would like to do & 26.9 \\
Exercise “buddy” or partner & 24.2 \\
Transportation to gym & 22.8 \\
Group exercise classes at my VA & 20.3 \\
Group exercise classes in community & 20.3 \\
Periodic telephone calls that provide encouragement & 9.6 \\
\hline Note: Numbers reflect proportion of individuals who reported 3 on scale of 1 \\
(“Would not help”) to 3 (“Would help a lot”) for factors presented. \\
VA = Department of Veterans Affairs. \\
\hline \hline
\end{tabular}

\section{Statistical Analyses}

We created three mutually exclusive amputation groups based on the most proximal level of amputation: (1) PFA (e.g., toe, transmetatarsal, and Symes), (2) belowknee amputation (BKA), and (3) above-knee amputation (AKA). Descriptive analyses include the presentation, by level of amputation, of percentages (for categorical variables) and medians and interquartile ranges (for continuous variables) for demographic, amputation-related, health-related and PA-related characteristics. Pooling over all amputation levels, we then estimated relative risks (RRs) of being physically active for each of the characteristics considered. Odds ratios approximate RRs when the outcome is rare (e.g., $<10 \%$ ). However, when the outcome (e.g., being physically active) is common, as in our study, odds ratios can differ substantially from RRs and therefore should be interpreted differently [39]. To directly estimate univariate RRs of being physically active separately for each characteristic, RR regression was employed using a generalized linear model, specifying a log-link, Poisson family, and robust standard error estimates. Additionally, we conducted sensitivity analyses excluding the seven individuals who had an amputation $<12$ mo prior to completing the questionnaire and stratifying the RR regression analyses by amputation level. Model fit was assessed using deviance and Anscombe residuals as well as Cook's distance as a measure of leverage. In this descriptive study, statistical significance was not assessed; rather, our discussion highlights estimates for the study population as a whole and estimated differences that are of meaningful magnitude. All analyses were performed with Stata 11.2 (College Station, Texas).

\section{RESULTS}

Of the 161 people who completed a questionnaire, 3 were later determined to be ineligible because their amputations were $<6$ mo prior to completing the questionnaire, leaving 158 for analyses. Of the nonparticipants, $53(22.2 \%)$ reported that they had not had an amputation, 7 were reported to be deceased, and 11 (4.6\%) were never contacted because of an incorrect address and telephone number. Thus, out of 326 apparently eligible individuals with valid contact information, 48.5 percent completed the questionnaire.

Table 3 presents the demographic, behavioral, and health-related characteristics of the study participants, who represent a predominantly male, older, nonemployed (e.g., retired, disabled, other), lower wealth population, but resemble the VHA patient population with limb loss [40]. Compared with individuals with a BKA or an AKA, a greater proportion of individuals with a PFA were $<55 \mathrm{yr}$ of age, unmarried, high school graduates or less, low wealth, had their amputation more recently or did not report their time since amputation, and had a body mass index $<25 \mathrm{~kg} / \mathrm{m}^{2}$. Individuals with an AKA were more likely to have had their amputation because of trauma and 36 percent had their amputation more than 32 yr prior.

As presented in Table 1, 18.2, 37.3, and 42.5 percent of participants with a PFA, BKA, and AKA, respectively, reported performing vigorous exercise "often" prior to their amputation. With regard to current activities, walking or wheeling were the most commonly reported (64.6\%), followed by performing strengthening exercises (42.4\%), exercises prescribed by a physical or occupational therapist (31.7\%), gardening (30.7\%), and yard work (29.4\%). Bicycling (12.1\%), golfing (5.8\%), swimming (3.2\%), and other exercise in a pool (e.g., water aerobics, $4.0 \%$ ) were less frequently reported. While participation in walking/wheeling, yard work, and gardening was similar by amputation level, individuals with an AKA were more likely to report performing physical/ occupational therapy-prescribed exercises, strengthening exercises, and bicycling.

The most frequently reported barriers to PA were resource-related (55.1\%) and pain-related (53.2\%, Table 1). In general, a greater proportion of individuals with a BKA 
JRRD, Volume 51, Number 6, 2014

Table 3.

Demographic, behavioral, and health characteristics of Northwest Veterans with lower-limb loss, 2011. Numbers given are percentage of participants unless otherwise indicated.

\begin{tabular}{|c|c|c|c|}
\hline \multirow{2}{*}{ Characteristic } & \multicolumn{3}{|c|}{ Level of Amputation } \\
\hline & $\begin{array}{l}\text { Partial Foot } \\
\quad(n=55)\end{array}$ & $\begin{array}{c}\text { Below Knee } \\
\quad(n=62)\end{array}$ & $\begin{array}{l}\text { Above Knee } \\
\quad(n=41)\end{array}$ \\
\hline \multicolumn{4}{|l|}{ Age (yr) } \\
\hline $55-64$ & 27.3 & 47.5 & 53.9 \\
\hline $65-74$ & 29.1 & 32.8 & 18.0 \\
\hline$\geq 75$ & 27.3 & 9.8 & 20.5 \\
\hline \multicolumn{4}{|l|}{ Marital Status } \\
\hline Married or living with partner & 47.3 & 61.3 & 72.5 \\
\hline Never married & 18.2 & 4.8 & 0 \\
\hline Separated, divorced, or widowed & 34.5 & 33.9 & 27.5 \\
\hline \multicolumn{4}{|l|}{ Education } \\
\hline High school graduate or less & 30.9 & 25.8 & 22.5 \\
\hline \multicolumn{4}{|l|}{ Wealth } \\
\hline Have money for special things & 29.6 & 24.6 & 45.0 \\
\hline Have enough money to pay bills, but little spare money to buy extra or special things & 44.4 & 54.1 & 35.0 \\
\hline Have enough money to pay bills, but only because you have cut back on things & 11.1 & 16.4 & 12.5 \\
\hline Having difficulty paying bills, no matter what you do & 14.8 & 4.9 & 7.5 \\
\hline \multicolumn{4}{|l|}{ Time Since Amputation } \\
\hline 6-12 mo & 9.1 & 1.6 & 2.4 \\
\hline $1-3 \mathrm{yr}$ & 16.4 & 12.9 & 14.6 \\
\hline $3-8 \mathrm{yr}$ & 25.5 & 27.4 & 14.6 \\
\hline $8-32 \mathrm{yr}$ & 12.7 & 30.7 & 24.4 \\
\hline$>32 \mathrm{yr}$ & 10.9 & 19.4 & 36.6 \\
\hline Uses manual wheelchair & 10.9 & 25.4 & 33.3 \\
\hline Uses power chair/scooter & 1.8 & 1.7 & 20.5 \\
\hline \multicolumn{4}{|l|}{ Body Mass Index $\left(\mathrm{kg} / \mathrm{m}^{2}\right)$} \\
\hline$<25.0$ & 33.3 & 19.7 & 25.0 \\
\hline $25.0-29.9$ & 22.2 & 41.0 & 32.5 \\
\hline $30.0-34.9$ & 25.9 & 23.0 & 27.5 \\
\hline$\geq 35.0$ & 18.5 & 16.4 & 15.0 \\
\hline \multicolumn{4}{|l|}{ Continuous Measures, Median (IQR) } \\
\hline Physical Health $t$-Score & $34.9(30,37)$ & $32.4(27,37)$ & $34.9(30,37)$ \\
\hline Mental Health $t$-Score & $44.7(39,53)$ & $43.5(39,51)$ & $45.8(40,51)$ \\
\hline Pain & $4.0(3,6)$ & $5.0(3,8)$ & $5.0(3,7)$ \\
\hline Pain Interference & $58.5(56,64)$ & $59.9(54,65)$ & $60.6(55,65)$ \\
\hline \multicolumn{4}{|c|}{$\begin{array}{l}\text { Note: Missing category is shown for variables with }>10 \text { missing values. Numbers missing for other variables are as follows: age }(n=3) \text {, race }(n=2) \text {, marital status } \\
(n=1) \text {, education }(n=1) \text {, employment status }(n=1) \text {, mobility status }(n=3) \text {, use of wheelchair }(n=5) \text {, body mass index }(n=3) \text {, physical health score }(n=2) \text {, men- } \\
\text { tal health score }(n=6) \text {, pain }(n=1) \text {, and pain interference }(n=4) \text {. } \\
\text { *One of these people reported that he/she was waiting for new prosthesis. } \\
\text { IQR = interquartile range. }\end{array}$} \\
\hline
\end{tabular}


reported barriers to PA; one exception was fear of falling, which was most frequently reported by individuals with an AKA.

Approximately 43 percent of people with amputation were classified as physically active (see "Methods" section and Table 4). Having greater wealth and a higher physical health score, being frequently vigorously active prior to amputation, watching $<5 \mathrm{~h} / \mathrm{d}$ of television, and not reporting knowledge-related barriers and lack of interest were associated with being physically active. Generally, trends observed for the overall population were also apparent in results stratified by amputation level, though patterns for those with a BKA and AKA differed somewhat from those with a PFA (Appendix Table A1, available online only). Results did not change appreciably when we excluded the seven people with an amputation $<12$ yr prior (Appendix Table A2).

PA enablers are presented in Table 2 . The most commonly reported factors that might facilitate PA were financial assistance to join a gym (43.0\%) and support from a spouse or family members (35.7\%). Generally, enablers did not differ importantly by amputation level, with the exception that relatively few individuals with a PFA reported that specialized equipment would facilitate them becoming or staying active (Appendix Table A3, $11.3 \%, 40.3 \%$, and $26.8 \%$ in individuals with a PFA, BKA, and AKA, respectively).

\section{DISCUSSION}

In this study of older Veterans with LLA from four northwestern states, we found that recreational activities such as bicycling and swimming were relatively uncommon; a relatively large percentage of participants reported walking/wheeling, gardening and yard work, strength training, and physical or occupational therapy exercises. The strongest correlates of PA were higher wealth, low television watching, and history of frequent vigorous PA before the amputation. The proportion of individuals who were active who were $>75$ yr old or had a PFA was low, while activity levels were higher in those with an amputation due to trauma. Over half of respondents reported that pain or limited resources were major barriers to PA and the most commonly reported PA facilitator was financial assistance to join a gym. Nevertheless, lack of interest and knowledge emerged as the barriers inversely associated with activity.
Several other authors have observed either similar levels of activity across amputation levels or greater participation in PA among those with an AKA [15,19-20]. Findings from our study and others regarding activity and level of amputation are contrary to expectations that individuals with more proximal amputations will be less active because of the greater energy expended with walking [41]. We suspect that the greater level of PA in people with an AKA may have been because they had a profile that was more consistent with a healthier lifestyle, including more education, wealth, and greater time since amputation, which may be a marker of resilience. Likewise, the greater likelihood of being active for individuals with an amputation due to trauma likely reflects the fact that these individuals were younger (mean of 63.3 vs $67.2 \mathrm{yr}$ ), less likely to have a PFA (17.2\% vs $45.0 \%)$, had longer time since amputation (mean of $28 \mathrm{yr}$ vs $8 \mathrm{yr}$ ), and engaged in more frequent exercise prior to their amputation.

While mounting evidence indicates that sedentary time is an important risk factor for type 2 diabetes, cardiovascular disease, metabolic syndrome, weight gain, and obesity, even among people who meet physical activity guidelines [42-43], no prior studies in people with LLA have investigated associations between sedentary time and PA. Though we assessed only one sedentary activity, television/video watching, our results indicate a strong inverse association. Future interventions to improve the health and well-being of people with LLA should aim to both reduce sedentary time and increase physical activity.

This study has a number of limitations that should be considered when interpreting our data. The self-reported nature of the data may be susceptible to social desirability and recall bias. In defining being active, we estimated exercise intensity based on published MET values, which were not specific to people with an amputation. Because energy expenditure for the same activity is higher in people with LLA $[3,41]$, we may have underestimated actual intensity, but because we employed the higher MET value when two or more were reasonable, this is less likely. Additionally, any underestimation of intensity level may have been counterbalanced by the fact that activities may be performed more slowly in order to keep the intensity at a self-perceived light or moderate level [41,44]. In any case, objective measures of PA would have been helpful to reduce reporting and recall bias. However, even objective PA monitors could not accurately measure many activities reported by this population such as weight lifting, gardening, yard work, bicycling, and exercise in the 
JRRD, Volume 51, Number 6, 2014

Table 4.

Overall distributions and associations with being physically active.

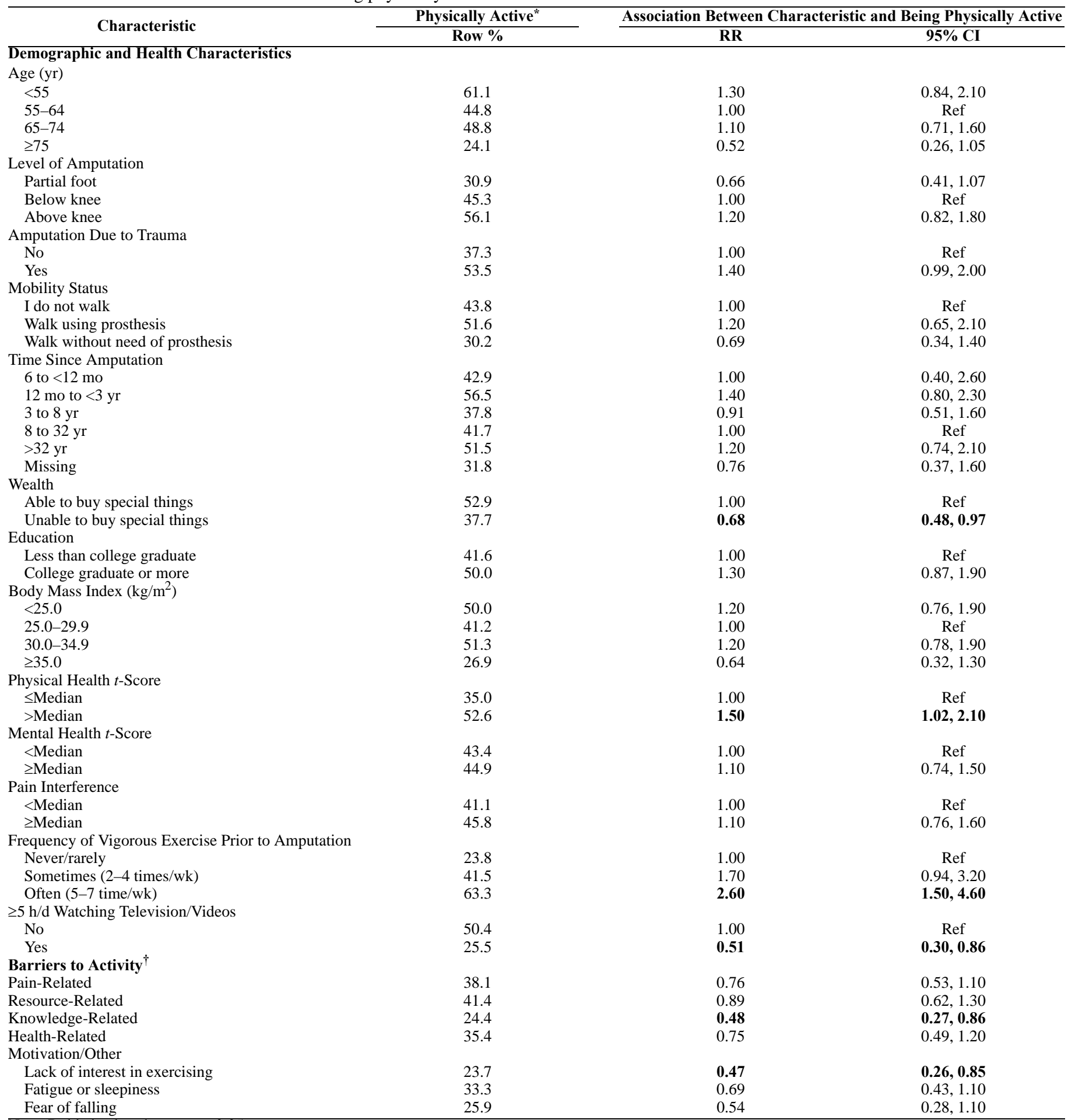

Note: Bolded values have a $p<0.05$.

${ }^{*}$ Definition of being physically active based on Centers for Disease Control and Prevention physical activity guidelines [1]. Active defined as $\geq 75$ min/wk of vigorous intensity activity, $\geq 150$ min of moderate-intensity activity, or equivalent combination of the two (see "Methods"). 69 (43.7\%) of 158 respondents were classified as physically active. Percentages present proportion of those physically active for whom row characteristic was present.

${ }^{\dagger}$ See Table 1 for more details.

$\mathrm{CI}=$ confidence interval, $\mathrm{Ref}=$ reference category, $\mathrm{RR}=$ relative risk. 
water, suggesting the need for innovative methods to more accurately measure PA other than ambulation.

Though we designed our questionnaire to be comprehensive, we chose brief items to reduce participation burden. For example, activity prior to amputation, the strongest correlate to current PA, was measured using a single item and the recall period varied by time since amputation. Nevertheless, this population is somewhat unique because all respondents had served in the military, and consequently, all participants had been required to perform regular vigorous activity at one time in their life. As a sensitivity analysis, we assessed the association between activity prior to amputation and being currently physically active among people who had their amputation $<10$ versus $\geq 10$ yr prior. In both strata, there was a consistent and strong association between prior activity and current activity. Additionally, we did not ask about PA barriers related to self-consciousness. We provided space for barriers not specified; no individuals listed self-consciousness, though future studies should consider explicitly asking about this barrier to assess its importance.

While our response rate is good for a mailed survey with no financial incentive (and exceeded that of nearly all other similar studies in people with LLA $[15,17,19,45])$, about half of selected individuals did not to complete the survey, the majority of participants were older men, and the study was limited to a single region of the country, factors that should be considered when interpreting our study results. Characteristics of our study population mirror those of Veterans who receive their care at the VHA; current estimates indicate that approximately 83 percent of VHA users are white (non-Hispanic) and 43 percent are $65 \mathrm{yr}$ of age or older [46]. However, because this study was conducted in VHA users, there were relatively few women, younger individuals, and non-whites. Studies of the general U.S. population have indicated higher levels of PA among people in the western United States [47-48]; thus, the activity levels in individuals in the current study may be higher than what might be observed in other regions of the country. Nevertheless, global and physical health scores were nearly 2 standard deviations below the general population mean, while mental health scores were about a half standard deviation below the general population mean [49-50], indicating that our study population was not especially healthy.

This study also has a number of strengths. Our study sample included a heterogeneous sample in terms of etiology, level of amputation, and time since amputation, as well as those with a PFA, who have not previously been included in studies such as this. We used a comprehensive questionnaire with validated measures when possible. As a result, we were able to investigate associations between a large variety of factors and PA.

\section{CONCLUSIONS}

Findings from this study indicate several areas for future research. Notably, future interventions should include individuals with a PFA, who were particularly inactive. In individuals with a PFA, illness- and knowledgerelated barriers were strongly correlated with not being physically active, perhaps because they have fewer interactions with clinical professionals with a rehabilitation/PA focus. Like most prior studies [14-15,17-19,21], our study included predominantly men; more research is needed to understand PA barriers and enablers in women with LLA. There is also a need to increase the number of healthcare/ exercise professionals who are knowledgeable about the special needs and barriers of people with LLA. Future interventions targeted at patients might involve a clinician or prosthetist regularly assessing a person's PA interests and sharing information about relevant community and/or health system resources. Social workers, recreational therapists, and veterans service organizations may help to address financial barriers that limit access to those resources. Findings from our study reinforce that addressing motivation for exercise is important, just as it is in the general population. Future interventions might employ motivational interviewing techniques to encourage participants to consider the potential benefits of becoming more physically active and setting PA goals that fit with their current fitness, functional capacity, and financial means. Involving spouses, family members, and/or peers may be particularly helpful for this population to overcome motivational and other barriers. While the recommendation to encourage more family and peer support has been represented in the literature on health promotion [51], the literature is quite sparse on any interventions that involve family or peer support to increase PA in adults with LLA or other disabilities [52]. A peer mentoring model has been effective to reduce feelings of depression and general self-efficacy in people with LLA but has not been tested with PA as an outcome [53]. Finally, more research is also needed to quantify the physical and mental health benefits that can be accrued with different types and amounts of PA. 


\section{ACKNOWLEDGMENTS}

\section{Author Contributions:}

Study concept and design: A. J. Littman, E. J. Boyko, M. L. Thompson, J. K. Haselkorn, B. J. Sangeorzan, D. E. Arterburn.

Analysis and interpretation of data: A. J. Littman, E. J. Boyko, M. L. Thompson, J. K. Haselkorn, B. J. Sangeorzan, D. E. Arterburn. Drafting of manuscript: A. J. Littman.

Critical revision of manuscript for important intellectual content: A. J. Littman, E. J. Boyko, M. L. Thompson, J. K. Haselkorn, B. J. Sangeorzan, D. E. Arterburn, J. K. Haselkorn, E. J. Boyko. Statistical analysis: A. J. Littman.

Obtaining funding: A. J. Littman.

Administrative, technical, or material support: A. J. Littman, E. J. Boyko, M. L. Thompson, J. K. Haselkorn, B. J. Sangeorzan, D. E. Arterburn.

Study supervision: A. J. Littman.

Financial Disclosures: The authors have declared that no competing interests exist.

Funding/Support: This material was based on work supported in part by the VA Office of Research and Development Cooperative Studies Program. The Seattle Epidemiologic Research and Information Center of the VA provided support for this research. Dr. Littman's time was also supported by a VA Rehabilitation Research and Development Career Development Award (\#6982).

Institutional Review: All study procedures were approved by the VA Puget Sound Institutional Review Board; a waiver of documentation of written informed consent was received.

Participant Follow-Up: The authors have no plans to inform the participants of the publication of this study.

Disclaimer: Portions of this material were presented at the Society for Behavioral Medicine Meeting in San Francisco in March 2013. The contents of this article do not represent the views of the VA or the U.S. Government.

\section{REFERENCES}

1. Office of Disease Prevention and Health Promotion. Physical activity guidelines for Americans [Internet].Washington (DC): Department of Health and Human Services; 2008 [updated 2014 Jul 29]. Available from: http://www.health.gov/paguidelines/guidelines/default.aspx

2. Ham SA, Kruger J, Tudor-Locke C. Participation by US adults in sports, exercise, and recreational physical activities. J Phys Act Health. 2009;6(1):6-14. [PMID:19211953]

3. Genin JJ, Bastien GJ, Franck B, Detrembleur C, Willems PA. Effect of speed on the energy cost of walking in unilateral traumatic lower limb amputees. Eur J Appl Physiol. 2008; 103(6):655-63. [PMID:18478251] http://dx.doi.org/10.1007/s00421-008-0764-0

4. Göktepe AS, Cakir B, Yilmaz B, Yazicioglu K. Energy expenditure of walking with prostheses: Comparison of three amputation levels. Prosthet Orthot Int. 2010;34(1):
31-36. [PMID:20196687]

http://dx.doi.org/10.3109/03093640903433928

5. Rose HG, Schweitzer P, Charoenkul V, Schwartz E. Cardiovascular disease risk factors in combat veterans after traumatic leg amputations. Arch Phys Med Rehabil. 1987; 68(1):20-23. [PMID:3800619]

6. Gailey R, Allen K, Castles J, Kucharik J, Roeder M. Review of secondary physical conditions associated with lower-limb amputation and long-term prosthesis use. J Rehabil Res Dev. 2008;45(1):15-29. [PMID:18566923] http://dx.doi.org/10.1682/JRRD.2006.11.0147

7. Dudek NL, Marks MB, Marshall SC, Chardon JP. Dermatologic conditions associated with use of a lower-extremity prosthesis. Arch Phys Med Rehabil. 2005;86(4):659-63. [PMID:15827914] http://dx.doi.org/10.1016/j.apmr.2004.09.003

8. Cooper RA, Quatrano LA, Axelson PW, Harlan W, Stineman M, Franklin B, Krause JS, Bach J, Chambers H, Chao EY, Alexander M, Painter P. Research on physical activity and health among people with disabilities: A consensus statement. J Rehabil Res Dev. 1999;36(2):142-54. [PMID:10661530]

9. Rimmer JH. Health promotion for people with disabilities: The emerging paradigm shift from disability prevention to prevention of secondary conditions. Phys Ther. 1999;79(5): 495-502. [PMID:10331753]

10. Rimmer JH, Braddock D. Health promotion for people with physical, cognitive and sensory disabilities: An emerging national priority. Am J Health Promot. 2002;16(4):220-24, ii. [PMID:11913327] http://dx.doi.org/10.4278/0890-1171-16.4.220

11. Ziegler-Graham K, MacKenzie EJ, Ephraim PL, Travison TG, Brookmeyer R. Estimating the prevalence of limb loss in the United States: 2005 to 2050. Arch Phys Med Rehabil. 2008;89(3):422-29. [PMID:18295618] http://dx.doi.org/10.1016/j.apmr.2007.11.005

12. Dillingham TR, Pezzin LE, MacKenzie EJ. Limb amputation and limb deficiency: Epidemiology and recent trends in the United States. South Med J. 2002;95(8):875-83. [PMID:12190225]

13. Veterans Health Administration. Amputation system of care [Internet].Washington (DC): Department of Veterans Affairs; 2012 Aug 15. VHA Handbook 1172.03. Available from: http://www.va.gov/vhapublications/ViewPublication.asp?pub ID $=2774$

14. Kegel B, Carpenter ML, Burgess EM. Functional capabilities of lower extremity amputees. Arch Phys Med Rehabil. 1978;59(3):109-20. [PMID:646596]

15. Kegel B, Webster JC, Burgess EM. Recreational activities of lower extremity amputees: A survey. Arch Phys Med Rehabil. 1980;61(6):258-64. [PMID:7377953] 
16. Jones L, Hall M, Schuld W. Ability or disability? A study of the functional outcome of 65 consecutive lower limb amputees treated at the Royal South Sydney Hospital in 19881989. Disabil Rehabil. 1993;15(4):184-88.

[PMID:8219247]

http://dx.doi.org/10.3109/09638289309166010

17. Burger H, Marincek C. The life style of young persons after lower limb amputation caused by injury. Prosthet Orthot Int. 1997;21(1):35-39. [PMID:9141124]

18. Legro MW, Reiber GE, Czerniecki JM, Sangeorzan BJ. Recreational activities of lower-limb amputees with prostheses. J Rehabil Res Dev. 2001;38(3):319-25. [PMID:11440263]

19. Kars C, Hofman M, Geertzen JH, Pepping GJ, Dekker R. Participation in sports by lower limb amputees in the Province of Drenthe, The Netherlands. Prosthet Orthot Int. 2009;33(4):356-67. [PMID:19947822] http://dx.doi.org/10.3109/03093640902984579

20. Couture M, Caron CD, Desrosiers J. Leisure activities following a lower limb amputation. Disabil Rehabil. 2010; 32(1):57-64. [PMID:19925277]

http://dx.doi.org/10.3109/09638280902998797

21. da Silva R, Rizzo JG, Gutierres Filho PJ, Ramos V, Deans S. Physical activity and quality of life of amputees in southern Brazil. Prosthet Orthot Int. 2011;35(4):432-38. [PMID:22042373] http://dx.doi.org/10.1177/0309364611425093

22. Blauwet C, Willick SE. The Paralympic Movement: Using sports to promote health, disability rights, and social integration for athletes with disabilities. PM R. 2012;4(11): 851-56. [PMID:23174549] http://dx.doi.org/10.1016/j.pmrj.2012.08.015

23. Harvey ZT, Potter BK, Vandersea J, Wolf E. Prosthetic advances. J Surg Orthop Adv. 2012;21(1):58-64. [PMID:22381512]

24. Laferrier JZ, Gailey R. Advances in lower-limb prosthetic technology. Phys Med Rehabil Clin N Am. 2010;21(1): 87-110. [PMID:19951780] http://dx.doi.org/10.1016/j.pmr.2009.08.003

25. Dillman D. Mail and internet surveys: The tailored design method-2007 update with new internet, visual, and mixed-mode guide. New York (NY): Wiley; 2006.

26. Dirmaier J, Harfst $T$, Koch U, Schulz H. Incentives increased return rates but did not influence partial nonresponse or treatment outcome in a randomized trial. J Clin Epidemiol. 2007;60(12):1263-70. [PMID:17998081] http://dx.doi.org/10.1016/j.jclinepi.2007.04.006

27. Edwards P, Cooper R, Roberts I, Frost C. Meta-analysis of randomised trials of monetary incentives and response to mailed questionnaires. J Epidemiol Community Health. 2005;59(11):987-99. [PMID:16234429] http://dx.doi.org/10.1136/jech.2005.034397
28. Godin G, Shephard RJ. A simple method to assess exercise behavior in the community. Can J Appl Sport Sci. 1985; 10(3):141-46. [PMID:4053261]

29. Washburn RA, Zhu W, McAuley E, Frogley M, Figoni SF. The physical activity scale for individuals with physical disabilities: Development and evaluation. Arch Phys Med Rehabil. 2002;83(2):193-200. [PMID:11833022] http://dx.doi.org/10.1053/apmr.2002.27467

30. Kriska A. Modifiable Activity Questionnaire. Med Sci Sports Exerc. 1997;29(6 Suppl):73-78.

31. Pettee Gabriel K, McClain JJ, Schmid KK, Storti KL, Ainsworth BE. Reliability and convergent validity of the pastweek Modifiable Activity Questionnaire. Public Health Nutr. 2011;14(3):435-42. [PMID:20843404] http://dx.doi.org/10.1017/S1368980010002612

32. Craig CL, Marshall AL, Sjöström M, Bauman AE, Booth ML, Ainsworth BE, Pratt M, Ekelund U, Yngve A, Sallis JF, Oja P. International physical activity questionnaire: 12country reliability and validity. Med Sci Sports Exerc. 2003;35(8):1381-95. [PMID:12900694] http://dx.doi.org/10.1249/01.MSS.0000078924.61453.FB

33. Ainsworth BE, Haskell WL, Herrmann SD, Meckes N, Bassett DR Jr, Tudor-Locke C, Greer JL, Vezina J, WhittGlover MC, Leon AS. 2011 Compendium of Physical Activities: A second update of codes and MET values. Med Sci Sports Exerc. 2011;43(8):1575-81. [PMID:21681120] http://dx.doi.org/10.1249/MSS.0b013e31821ece12

34. Rimmer JH, Wang E, Smith D. Barriers associated with exercise and community access for individuals with stroke. J Rehabil Res Dev. 2008;45(2):315-22. [PMID:18566948] http://dx.doi.org/10.1682/JRRD.2007.02.0042

35. Rosenberg DE, Norman GJ, Wagner N, Patrick K, Calfas KJ, Sallis JF. Reliability and validity of the Sedentary Behavior Questionnaire (SBQ) for adults. J Phys Act Health. 2010;7(6):697-705. [PMID:21088299]

36. Reeve BB, Hays RD, Bjorner JB, Cook KF, Crane PK, Teresi JA, Thissen D, Revicki DA, Weiss DJ, Hambleton RK, Liu H, Gershon R, Reise SP, Lai JS, Cella D; PROMIS Cooperative Group. Psychometric evaluation and calibration of health-related quality of life item banks: Plans for the Patient-Reported Outcomes Measurement Information System (PROMIS). Med Care. 2007;45(5 Suppl 1):S22-31. [PMID:17443115] http://dx.doi.org/10.1097/01.mlr.0000250483.85507.04

37. Amtmann D, Cook KF, Jensen MP, Chen WH, Choi S, Revicki D, Cella D, Rothrock N, Keefe F, Callahan L, Lai JS. Development of a PROMIS item bank to measure pain interference. Pain. 2010;150(1):173-82. [PMID:20554116] http://dx.doi.org/10.1016/j.pain.2010.04.025

38. Revicki DA, Kawata AK, Harnam N, Chen WH, Hays RD, Cella D. Predicting EuroQol (EQ-5D) scores from the patient-reported outcomes measurement information system 
(PROMIS) global items and domain item banks in a United States sample. Qual Life Res. 2009;18(6):783-91.

[PMID:19472072]

http://dx.doi.org/10.1007/s11136-009-9489-8

39. Lumley T, Kronmal R, Ma S. Relative risk regression in medical research: Models, contrasts, estimators, and algorithms. UW Biostatistics Working Paper Series. 2006;(Paper 293):1-24.

40. Mayfield JA, Reiber GE, Maynard C, Czerniecki JM, Caps MT, Sangeorzan BJ. Trends in lower limb amputation in the Veterans Health Administration, 1989-1998. J Rehabil Res Dev. 2000;37(1):23-30. [PMID:10847569]

41. Gailey RS, Wenger MA, Raya M, Kirk N, Erbs K, Spyropoulos P, Nash MS. Energy expenditure of trans-tibial amputees during ambulation at self-selected pace. Prosthet Orthot Int. 1994;18(2):84-91. [PMID:7991365]

42. Raynor, HA, DS Bond, PS Freedson, SB Sisson. Sedentary behaviors, weight, and health and disease risks. J Obes. 2012;2012:852743.

43. Owen N, Healy GN, Matthews CE, Dunstan DW. Too much sitting: The population health science of sedentary behavior. Exerc Sport Sci Rev. 2010;38(3):105-13. [PMID:20577058] http://dx.doi.org/10.1097/JES.0b013e3181e373a2

44. Nowroozi F, Salvanelli ML, Gerber LH. Energy expenditure in hip disarticulation and hemipelvectomy amputees. Arch Phys Med Rehabil. 1983;64(7):300-3. [PMID:6860105]

45. Deans SA, McFadyen AK, Rowe PJ. Physical activity and quality of life: A study of a lower-limb amputee population. Prosthet Orthot Int. 2008;32(2):186-200.

[PMID:18569887]

http://dx.doi.org/10.1080/03093640802016514

46. VA Benefits \& Health Care Utilization National Center for Veterans Analysis and Statistics. Washington (DC): Department of Veterans Affairs; 2013 [cited 2013 April 29].

47. Pleis JR, Lethbridge-Cejku M. Summary health statistics for U.S. adults: National Health Interview Survey, 2005. Vital Health Stat 10. 2006;(232):1-153. [PMID:17252928]

48. Carlson SA, Fulton JE, Galuska DA, Kruger J, Lobelo F, Loustalot FV; Centers for Disease Control and Prevention (CDC). Prevalence of self-reported physically active adults-United States, 2007. MMWR Morb Mortal Wkly Rep. 2008;57(48):1297-1300. [PMID:19052527]
49. Fries JF, Bruce B, Cella D. The promise of PROMIS: Using item response theory to improve assessment of patient-reported outcomes. Clin Exp Rheumatol. 2005; 23(5, Suppl 39):S53-57. [PMID:16273785]

50. Hays RD, Bjorner JB, Revicki DA, Spritzer KL, Cella D. Development of physical and mental health summary scores from the patient-reported outcomes measurement information system (PROMIS) global items. Qual Life Res. 2009;18(7):873-80. [PMID:19543809] http://dx.doi.org/10.1007/s11136-009-9496-9

51. Eyler AA, Brownson RC, Donatelle RJ, King AC, Brown D, Sallis JF. Physical activity social support and middleand older-aged minority women: Results from a US survey. Soc Sci Med. 1999;49(6):781-89. [PMID:10459889] http://dx.doi.org/10.1016/S0277-9536(99)00137-9

52. Hogg L, Grant A, Garrod R, Fiddler H. People with COPD perceive ongoing, structured and socially supportive exercise opportunities to be important for maintaining an active lifestyle following pulmonary rehabilitation: A qualitative study. J Physiother. 2012;58(3):189-95. [PMID:22884186] http://dx.doi.org/10.1016/S1836-9553(12)70110-8

53. Wegener ST, Mackenzie EJ, Ephraim P, Ehde D, Williams R. Self-management improves outcomes in persons with limb loss. Arch Phys Med Rehabil. 2009;90(3):373-80. [PMID:19254599] http://dx.doi.org/10.1016/j.apmr.2008.08.222

Submitted for publication June 28, 2013. Accepted in revised form February 12, 2014.

This article and any supplementary material should be cited as follows:

Littman AJ, Boyko EJ, Thompson ML, Haselkorn JK, Sangeorzan BJ, Arterburn DE. Physical activity barriers and enablers in older Veterans with lower-limb amputation. J Rehabil Res Dev. 2014;51(6):895-906.

http://dx.doi.org/10.1682/JRRD.2013.06.0152

ResearcherID/ORCID: Alyson J. Littman, PhD: A-64092012

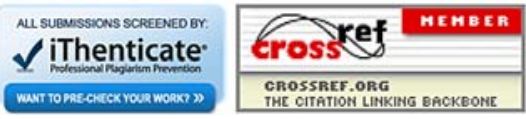

